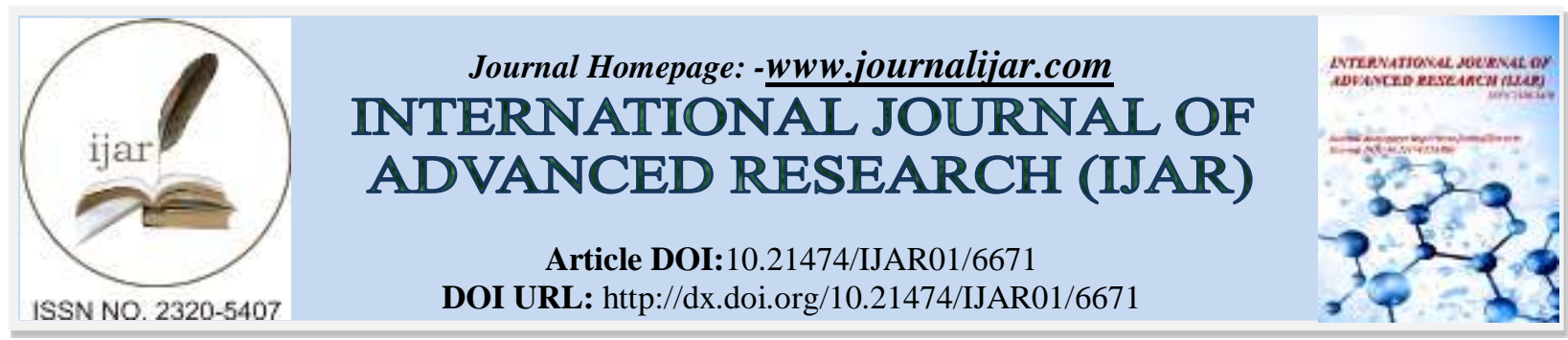

RESEARCH ARTICLE

\title{
CORRELATION BETWEEN INTERLEUKIN 17 AND TRANSFORMING GROWTH FACTOR BETA WITH HABITUAL ABORTION IN WOMEN INFECTED WITH CYTOMEGALOVIRUS.
}

\section{Qasim mohammed banja ${ }^{1}$, thamer mutlk ${ }^{1}$, samah a. Jassam $^{1}$, mohamed kadum al-araji ${ }^{1}$ and qays ahmed al-} kafaji².

1. Department of Clinical Laboratory Sciences, College of Pharmacy, AL-Mustansiriyah University. Baghdad, Iraq.

2. Kamal Al-Samarraee Teaching Hospital for Infertility and IVF.

\section{Manuscript Info}

\section{Manuscript History}

Received: 05 January 2018

Final Accepted: 07 February 2018

Published: March 2018

Keywords:-

IL17, TGF $\beta$, RSL, CMV infection.

\section{Abstract}

Background: Interleukin 17 and transforming growth factor beta (TGF- $\beta$ ) are known with their effect on immune cells, and play a key role in the pathogenesis of some cell-mediated diseases, such as autoimmune diseases and cancer. Recurrent pregnancy loss (RPL) is a challenging field in generative medicine, the etiology of RPL is still not fully understood, and the knowledge regarding guides-based diagnostic and treatment are limited.

Aim of study: The aim of this study was to investigate the the role of Interleukin 17 (IL17) and transforming growth factor beta (TGF $\beta$ ) to CMV immunoglobulin in RPL in Iraqi patients infected with Cytomegalovirus (CMV), and to correlate them with RPL status, compared to the healthy control.

Patients and methods: This study included 88 pregnant women, 37 women represented the healthy control, where no history of recurrent abortion. 24 patients were with two or more recurrent abortion, and 27 patients had a single abortion. The sera levels of IL17, TGF $\beta$, and antiCMV IgG, IgM were measured in blood patients by the enzyme-linked immunosorbent assay (ELISA).

Results: The results revealed high levels of anti-CMV IgG in RPL patients compared to the healthy control $(83.3 \%, 96.3 \%$ and $56.8 \%$ respectively; $(\mathrm{p}<0.001)$. While no significant difference was noted in levels of IgM anti-CMV, IL17 and TGF $\beta$ among the studied groups $(\mathrm{p}<0.001)$.

Conclusion: There is a strong correlation between elevated anti-CMV IgG and RPL. However, IgM anti-CMV IL17 and TGF $\beta$ were correlated directly with in RSL patients compared with healthy control.

Copy Right, IJAR, 2018,. All rights reserved.

\section{Introduction:-}

Recurrent pregnancy loss is a devastating problem in women's health, it is commonly occurred, and nearly $15 \%$ of clinically recorded pregnancies are ended with recurrent pregnancy loss (RPL), although many more pregnancies were lots even before clinically recognised. RPL is defined as a three times recurrent pregnancy loss prior to 20 weeks, since the last menstrual period (Macklon et al 2002). There are numerous unsolved questions concerning 
RPL etiology, management, and evaluation (Ford and Schust 2009). Previous studies reveal that, at least 50\% of RPL are related to unknown cause (Stephenson 1996). The incidence of RPL is approximately 1 in 300 pregnancies, although, previous studies showed that $1 \%$ to $2 \%$ of women experience RPL (Stephenson 1996). Many causative factors were suggested to explain RPL, such as anatomic, immunological, genetic, endocrine, infectious, thrombophilia, and environmental factors (Macklon et al 2002). RPL was correlated with specific viral infections including: measles, herpes simplex virus, and cytomegalovirus, which are suspected to play a key role in RPL with incidence of $0.5 \%$ (Stephenson 1996) to $5 \%$ (Fowler 1992).

\section{Recurrent pregnancy loss and cytomegalovirus (CMV) infection:-}

Cytomegalovirus is a DNA virus, member of herpesvirida family, it infects human only (Fowler 1992). Statistical studies revealed that about $50 \%$ of women in a reproductive age showed a CMV infection. Mostly, CMV is transmitted via blood transfusion, sexual contact, and exposure to infected saliva and infected body fluids (Duff 2007). CMV infection is a worldwide separated; the serological test showed a positivity ranging from $40 \%$ to $90 \%$ in developed countries (Sherkat 2014, Cannon 2010). During pregnancy CMV primary infection or recurrent CMV may occur. Fortunately, CMV congenital transmission to the foetus showed a low rate (Fowler 1992); if the infection occurs at the first three months, it would cause pregnancy loss (Sherkat 2014). When CMV infection occurs at the second half of the pregnancy, $90 \%$ of survived children will be born with CMV complications as mental retardation, vision impairment, hearing loss (Kriel et al 1970, Gaytant et al 2003, Nigro and Adler 2013). Previous studies showed unclear correlating between CMV infection with pregnancy loss. Furthermore, the mechanisms and immunoreactions combined with CMV and pregnancy are not fully clarified yet.

\section{IL-17 and TGF $\beta$ and recurrent pregnancy loss:-}

IL-17 (also known as IL-17A) plays a crucial role in immunity against extracellular pathogens and intracellular pathogens, also, it is involved in the pathogenesis of many autoimmune and inflammatory diseases (Happel et al 2005, Kuwabara et al 2017). Different immune cells, such cells $\gamma \delta$ T-cell and T-cytotoxic cell produce IL-17 (Huang et al 2004). Dysregulation of immune response suppresses Th1-cell, Th17-cells but not Th2-cells, and that increases the incidence of autoimmune diseases (Kuwabara et al 2017). Previous studies showed that, increased level of IL-17 is correlated with over-generation of Th17-cells, combined with autoimmune diseases (Kuwabara et al 2017). Recent studies revealed a significant increase of Th-17 cells count in women with recurrent pregnancy lose, miscarriage, preeclampsia, and preterm birth (Darmochwal-Kolarz et al 2017, Darmochwal-Kolarz et al 2012, Ito et al 2010, Nakashima et al 2010).

IL-17 is known as a potent pro-inflammatory cytokine; recent studies manifest the role of IL-17 in developing inflammation process during autoimmune diseases and graft rejection (Gaffen 2009). Moreover, IL-17 influences the maturation process of dendritic cell; also, it prohibits the immune response induced by Th-cells, leading to immune tolerance (Gaffen 2009).

Transforming growth factor- $\beta$ (TGF- $\beta$ ) is produced by platelets, lymphocytes, neutrophils, and macrophages (Gaffen 2009). It is a pleiotropic polypeptide, it influences different biological activities, TGF- $\beta$ inhibits Blymphocytes, T-lymphocytes and natural killer cells proliferation, wound healing, inflammation, immune regulation, embryonic development and differentiation of adult stem cell (Gaffen 2009). In addition, TGB- $\beta$ reduces the output of pro-inflammatory cytokines, and it prevents the formation of major histocompatibility complex class II (MHC II) on cell membrane of antigen presenting cells ( $\mathrm{Li}$ et al 2006). Moreover, TGB- $\beta$ regulates the entry of cells to apoptosis (Walshe et al 2009). TGB- $\beta 1$ is the most studied member of TGB- $\beta$ family; it acts as an immunosuppressive factor on B and T lymphocytes, absence of this cytokine is correlated with autoimmune diseases as lupus and scleroderma (Letterio, Roberts 1998).

The actual role and the underlining mechanisms of CMV infection effect in RPL are not fully understood yet. Thus, this study focuses on the correlation between cytomegalovirus infection, levels of IL-17 and TGF $\beta$ with the recurrent pregnancy loss.

\section{Patients and methods:-}

This study included 88 pregnant women who, were admitted to the department of Obstetrics and Perinatology of Kamal Al-Samarrai hospital in Baghdad, Iraq, during the period from October 2015 to December 2016. The diagnosis was made depending on clinical examination and patient's medical history according to the criteria of Royal college of Obstetricians and Gynaecologists. Patients were grouped into the following groups: the healthy 
control group was included 37 healthy pregnant women without history of recurrent abortion, 27 women with history of one abortion, 24 women with history of two, or more recurrent abortions. Samples of peripheral blood were collected (non-fasting), into sterile gelatine tube, samples were incubated for one hour, then serum was separated by centrifuging at $4000 \mathrm{rpm}$ for 15 minutes. The Ethical committee of the Baghdad medical city hospital approved this study. The immunoenzymatic assay was used to measure levels of IL17, TGF $\beta 1$, and anti-CMV IgG, IgM in collected samples, using the following kits: CMV LgG, IgM avidity kit (Bioactive diagnostic, Germany), human TGF $\beta 1$ kit (Demeditec diagnostics, Germany) and human IL17 is manufactured by Biological Technology, China.

\section{Statistical analysis:-}

The statistical analysis was conducted using Anderson Darling test to test the distribution of continuous variables. Discrete variables presented using there number and percentage used to present the data, chi square test used to analyse the discrete variable, and statistical difference between studied groups was rated using one way ANOVA and Tukey`s multiple comparison. All experiments were carried out three times independently and the data was expressed as \pm SE. Binary logistic regression analysis used to calculate the odd ratio (OR) and their 95\% confidence intervals, when the outcome can be categorized into 2 binary levels, and if appropriate probability plot used to present the relationship. SPSS 20.0.0 software package was used to make the statistical analysis; $p$ value was considered a significant, when less than 0.05 .

\section{Results:-}

Levels of Anti-Cytomegalovirus (CMV) IgM and IgG:-

Results showed no significant difference in levels of anti-CMV IgM and IgG in patients with single or multi abortion, compared with the healthy control group. Anti-CMV IgM was negative in all included groups. In addition, anti-CMV IgG showed a different levels in each group: $31.5 \%$ in group with single abortion, $39.1 \%$ in multiple abortions compared with $18.5 \%$ in healthy control group, although differences were statistically non-significant as in figure 1 .
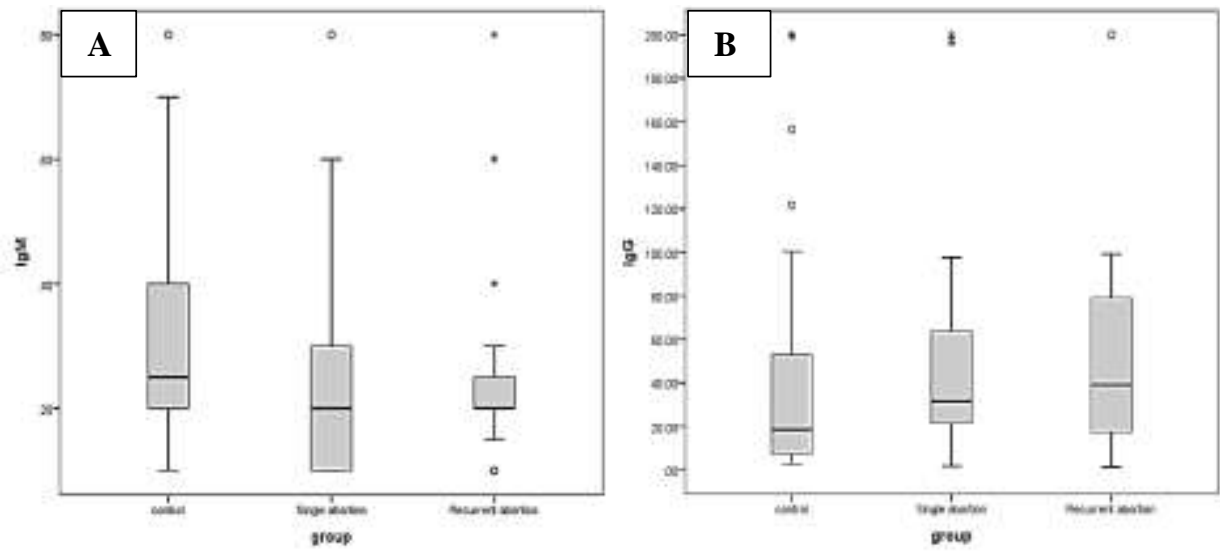

Figure 1: Levels of IL17 and TGF $\beta$. A: Box plot of IgM serum levels. B.Box plot of IgG serum levels. The grey box represents the interquartile range percentile, the black middle line represents the median, and the scatter points represent the outliers.

\section{IgG avidity:-}

Avidity is known as the degree of immune activity in which the polyclonal IgG molecules binds to multiple epitopes of the antigen (Hazell 2007). IgG validity results showed $0.65 \pm 0.25$ in healthy control group, while $0.60 \pm 0.06$ of validity was seen in women with single abortion. $0.68 \pm 0.05 \mathrm{IgG}$ validity was noted in patients with recurrent abortion. However, no significant difference was found in the avidity of studied groups. One way ANOVA was used in statistical analysis. Data was presented as mean $\pm \mathrm{SD}, \mathrm{p}<0.05$. 


\section{Correlation between IL17 and CMV infection:-}

Control group showed a distinctive correlation between anti-CMV IgM and IL17, on the other hand, a weak correlation between IL17 and anti CMV IgG was seen, as shown in table 2 and figure 2A. Single abortion group revealed inverse, weak correlation between IgG avidity and IL17, however no correlation was noted between IL17, $\mathrm{IgG}$ and IgM as illustrated in table 2 and figure 2B. Recurrent abortion group declared a direct, but weak correlation between IgG avidity and IL17. Although, there was a mild, direct correlation of IgM and IL17, as in figure 2 A, B and $\mathrm{C}$.
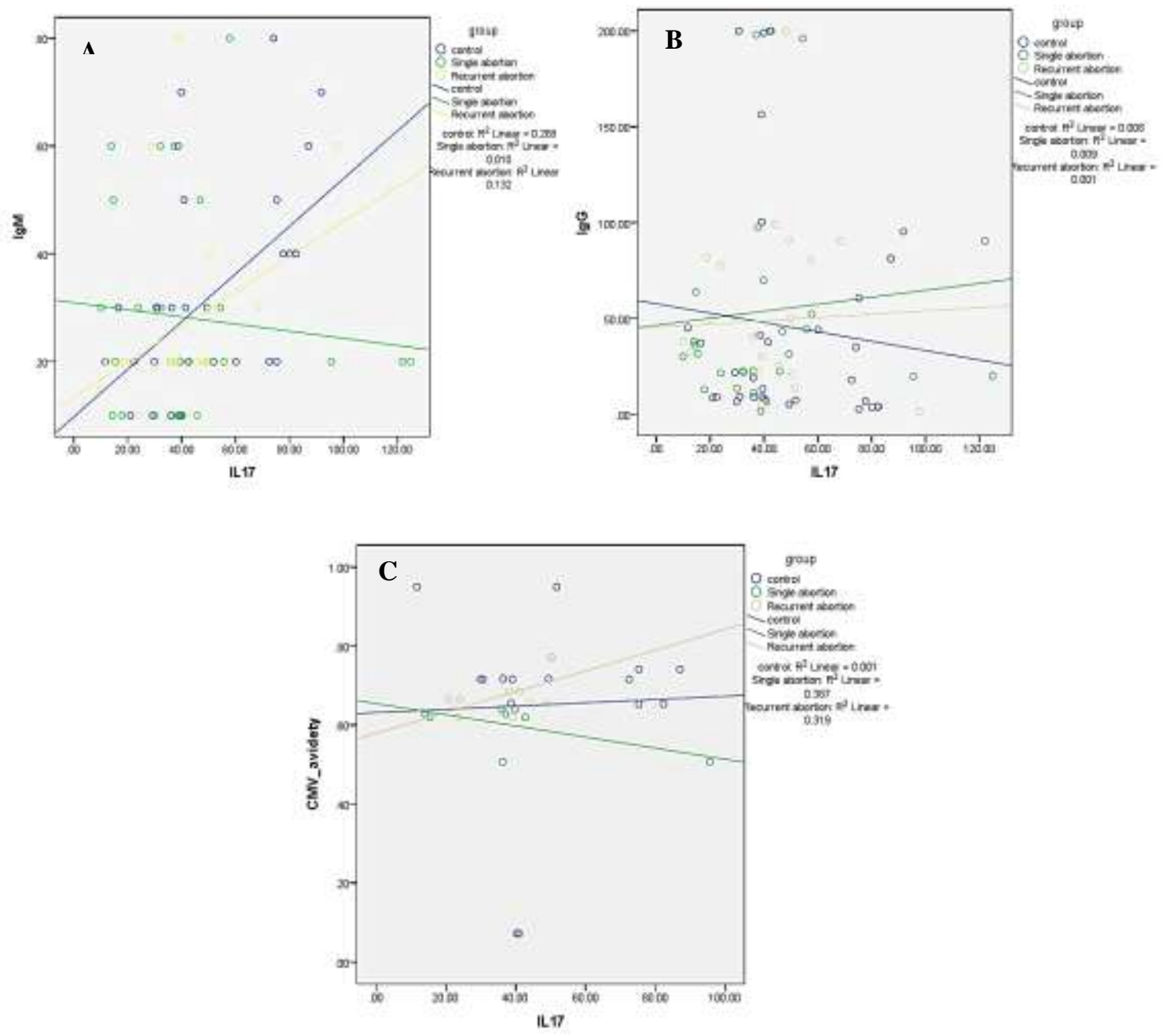

Figure 2: The correlation between IL17 and CMV infection . A: Scatter plot for the correlation between IL17 and IgM in all the studied groups, B: represents the correlation between IL17 and IgG in all the studied groups. C: shows the correlation between IL17 and IgG avidity in all the studied groups. Plots represent linear regression analysis. Blue represents the control group, green represents single abortion group and the orange represents multiple abortion groups.

The correlation between CMV infection and TGF:-

Results revealed an inverse, weak correlation with anti-IgM and IgG CMV with TGF in healthy control group as shown in figure $3 \mathrm{~A}$. While, no correlation was seen in single abortion group neither IgM nor IgG avidity with TGF, as illustrated in figure 3B. Recurrent abortion group also, showed no correlation between IgG, IgM and IgG avidity with TGF as in figure $3 \mathrm{C}$. 

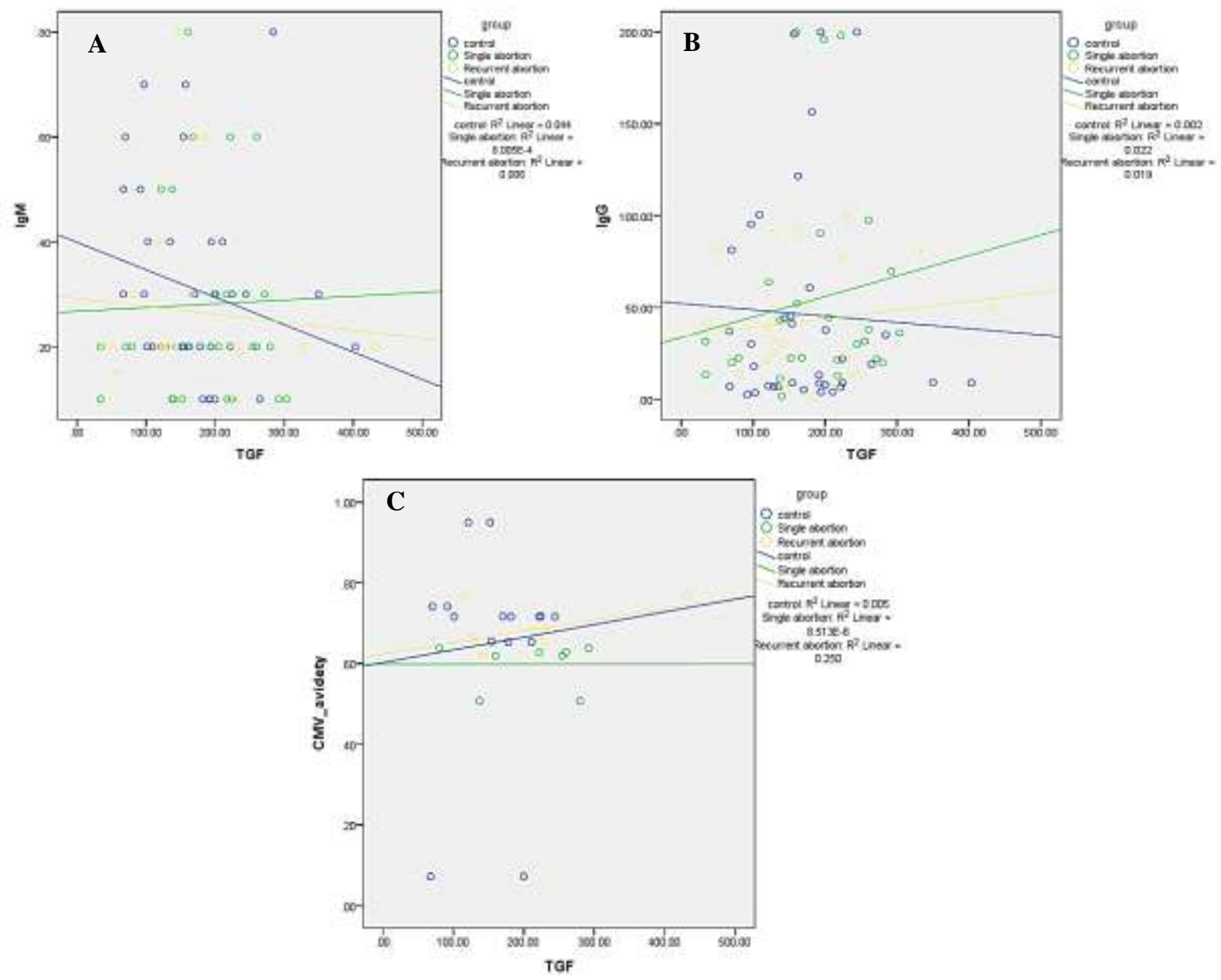

Figure 3.A: Scatter plot for the correlation between TGF and IgM in all the studied groups, B: scatter plot for the correlation between TGF and IgG in all the studied groups, C: scatter plot for the correlation between TGF and IgG avidity in all the studied groups. Blue represents the control group, green represents single abortion group and the orange represents multiple abortion group.

\section{History of past CMV infection:-}

There was a significant high proportion of patients had past infection in both recurrent and single abortion groups (83.3\% and 96.3\%) compared to control group (56.8\%). Recurrent abortion associated 3.8 folds compared to healthy control, with past CMV infection, while single abortion group associated 19.8 folds compared to control with past CMV infection.

\section{Is there any correlation Relationship between IL17 and TGF?:-}

Results showed that there was a weak (non-significant) inverse correlation between IL17 and TGF in both control and single abortion group. While, in RPL group the relationship remain weak but it become direct relationship between them as illustrate in figure 4. In addition, the lowest level of IL17 was seen in patients with multiple recurrent abortion, compared with patients with single abortion and healthy control group, $(40.05 \%, 42.47 \%$ and $48.40 \%$ respectively). However, no statistical significance was found. Furthermore, TGF $\beta$ results did not show any statistical differences between different groups, figure 4. 


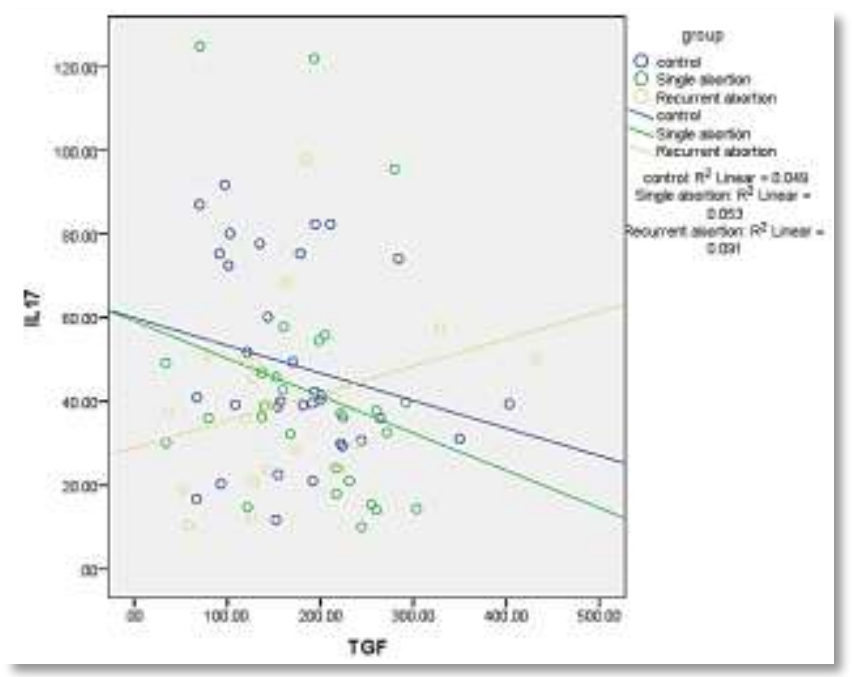

Figure 4: Scatter plot for the correlation between TGF and IL17 in all the studied groups, the plot is showing a linear regression analysis between IL17 and TGF levels according to the group. Blue represents the control group, green represents single abortion group and the orange represents multiple abortion group.

\section{Discussion:-}

Viruses had been implicated with both fetal morbidity and mortality during pregnancy and postpartum periods, the infection occur through either vaginal transmission and/or trans-placental (through circulation). CMV virus considered the most common concerned virus as probable reason of recurrent spontaneous abortion (RSA), in which CMV infection can cause either chronic or recurrent maternal infection (Nigro 2009). Current study, results referred to all included cases who were positive to CMV infection, had past CMV-infection, based on the negative IgM and the positive $\operatorname{IgG}$ with a high titre of $\operatorname{IgG}$ avidity. In addition, no significant difference was noted in serum $\operatorname{IgM}$ levels, $0.25 \mathrm{IU} / \mathrm{ml}$ in healthy control, $0.20 \mathrm{IU} / \mathrm{ml}$ for pregnant women with history of single abortion, and $0.20 \mathrm{IU} / \mathrm{ml}$ women with RPL. These findings were low compared to Zaki and Goda findings in a study involved 50 patients with unexplained RSA (defined as 3 or more consecutive spontaneous abortion), and 12 control (Zaki, Goda 2007). Zaki and Goda reported a positive IgM-CMV titre of $12 \%$ within the RSA patients compared to $16.7 \%$ in the control group, there results were close to what Odland and Hazell revealed (Odland et al 2001 and Hazell 2007). Another study showed a low seropositivity of 5.33\% for IgM CMV (Ahmed, Salman 2014). In addition, Hussan showed a higher seropositivity of $33.8 \%$ of IgM CMV titre (Hussan 2013). However, Ahmed explained the high levels of IgM-CMV, that the cases he studied suffered from another gynaecological problems including recurrent abortion, that caused a high proportion of women with positive IgM titre, these findings were reinforced with another study on Iraqi patients, that showed 8\% of IgM-CMV titre (Aljumaili et al 2014).

Our findings showed very low IgM CMV levels, that agreed with Sadik et al 2012, who revealed a 0\% CMV IgM in their study, that included pregnant women with chronic obstetric history (Sadik et al 2012). The low CMV IgM titre can be explained by that a primary CMV infection is usually acquired in the childhood period, so the serological susceptibility and the risk for primary infection with CMV is low during pregnancy compared to other viruses (Sadik et al 2012). Our results revealed that there was no significant difference in the levels of CMV IgG or CMV IgM among different groups, 11 patients had negative IgM in their sera in all the groups. The healthy control group had significantly lower IgG positive sera compared to single abortion group and recurrent abortion group $(56.8 \%, 96.3 \%$ and $83.3 \%$ respectively).

In this study pregnant women in healthy control group showed the lowest rate of positive IgG titter $56.8 \%$. Single abortion group 96.3\% and recurrent abortion group, our findings was in agreement with Odland et al 2001 in which they studied 182 normal pregnant women and 127 RSA Russian women, they reported $78 \%$ for control and $81.1 \%$ for RSA positive IgG titer, $\mathrm{p}=0.51$ (Hazell 2007). Our findings was higher than that of Sadik et al 2012 in Indian, which included 86 pregnant women with various history of chronic obstetric history, with $23.25 \%$ positive IgG (Sadik et al 2012), these differences were attributed to inclusion and exclusion criteria, as well as the pattern of CMV infection in Indian women compared to Iraqi women. However, previous study included Iraqi women has reported $47.7 \%$ positive IgG CMV titre of the pregnant women (Odland et al 2001). More recent study on pregnant 
women with RSA it is reported that $72.09 \%$ of patients with RSA had positive IgG CMV titre, which is close to our findings (Hananchi et al 2011). In Middle East country, the reported rate of CMV IgG seropositivity was $96.6 \%$ in Tunisia, 63.3\% in Saudi Arabia (Hananchi et al 2011, Al-Jiffri et al 2013). The majorities of previous studies were concurred about the high rate of IgG positivity for pregnant women with various obstetric problems including RSA, which indicated a link between CMV infection and RSA(Odland et al 2001, Hananchi et al 2011, Al-Jiffri et al 2013). However, IgG alone to diagnose CMV infection was not highly recommended, it must combine with IgG avidity to determine the onset of infection and its chronicity. In the current study IgG avidity was $0.65 \pm 0.25 \mathrm{IU} / \mathrm{ml}$ for the healthy control pregnant women, $0.60 \pm 0.06 \mathrm{IU} / \mathrm{ml}$ for single abortion group and $0.68 \pm 0.05 \mathrm{IU} / \mathrm{ml}$ for RSA group, there was no significant difference between them $\mathrm{p}<0.05$. That revealed that most of the infected patients with CMV had chronic infection.

In addition, the frequency of CMV infection was significantly higher in the recurrent abortion group (83.3\%) compared to healthy control group (56.8\%). All the infected CMV were positive to past CMV infection (defined as negative IgM, positive IgG and high titre IgG avidity).

An Egyptian study showed the frequency of CMV infection was 12\%, and it represented acute CMV infection using IgM PCR for diagnosis; however this study did not report the frequency of chronic CMV infection in included cases, since the focus was on CMV IgM only (Zaki, Goda 2007). Primary infection of CMV occurred during pregnancy was linked to $2^{\text {nd }}$ and $3^{\text {rd }}$ trimester complications like stillbirths and late abortion, RSA (Zaki, Goda 2007). Although, maternal recurrent infections with CMV infection lead to fetal infection (Pass; Anderson 2014).

it has lower risk to cause damage, making the primary CMV infection to be the most severe, the primary infection usually occur during childhood with higher prevalence in rural areas compared to urban (Hazell 2007). A study in Israel involved 6,126 cases, it found that $84.3 \%$ had chronic CMV infection, diagnosed based on positive anti-CMV IgG (Stein et al 1997).

IL17 was associated with recurrent abortion (Ozkan et al 2014). Our findings found that, IL17 in healthy control group was $48.40 \pm 22.88 \mathrm{ng} / \mathrm{ml}$, compared to $40.05 \pm 18.92 \mathrm{ng} / \mathrm{ml}$ in RSA group, . However, no significant difference was seen between them $\mathrm{p}>0.05$. Those findings disagreed with results of Ozkan et al 2014 . IL17 level was $62.7 \pm 7.8 \mathrm{ng} / \mathrm{ml}$ in RPL cases compared to $1.5 \pm 0.1 \mathrm{ng} / \mathrm{ml}$ in healthy control p<0.01 (Ozkan et al 2014), also it predicted, that IL17 at a cut point of $\geq 1.87 \mathrm{ng} / \mathrm{ml}$ had a good ability to discriminate pregnant women with RPL, referring to high levels of IL17 in RPL group compared to healthy control (Ozkan et al 2014). A possible explanation of this difference was, that IL17 polymorphism can cause different response, this hypothesis was reinforced by a study conducted by Najafi et al (2014). The study revealed that IL17F did not exert a statistical difference $\mathrm{p}<0.01$, while another form of IL17F (re763780) showed a significant difference between the two groups. However, the same study revealed that some Iraqi women were positive to IL17A (re2275913) form, which was not associated with RPL and there was not significant difference between RPL and healthy control group (Najafi et al 2014).

There was ongoing interest in literature to find the role of the immunological effect of cytokines in avidity, particularly in female marginal plasma and in the tissues of uteroplacental, for the homeostasis of the immune system, there must be an equilibrium among the cells effector and between the controller cells, (Raghupathy et al 2000; Giannubilo et al 2012).

The effect of Treg is to maintain the embryo- maternal acceptance, however the effect of IL17 producing T-helper seventeen cells in the normal and abnormal gravidity particularly in recurrent pregnancy lose need more study, Th17 cells considered a mediator of tissue distraction and inflammation (Fischer 2008). Liu et al declared that Th17/Treg cells ratio in patients with RPL is significantly higher compared to normal pregnant and non-pregnant females (Liu et al 2011). Immature predecessor cells is strongly inhibited by INF $\gamma$ and IL4 (Harrington et al 2005). in another study TGF $\beta$ reported in promote Th17 production and IL10 may not inhibit IL17 production (Naundorf et al 2009). The current study found a direct association between IL17 and TGF $\beta(p<0.05)$. In addition TGF $\beta$ was noted to increase IL17 level in serum. However, our study did not find a significant difference in TGF $\beta$ levels between RPL and healthy pregnant women $(\mathrm{p}<0.05)$, with a median of TGF $\beta$ in control group $162.5 \mathrm{ng} / \mathrm{ml}$ and in RPL group 145 $\mathrm{ng} / \mathrm{ml}$. 
Although, Ozkan et al 2014 results disagreed with our findings, he found that TGF $\beta$ was significantly higher in RPL women compared to healthy pregnant women control group $46.8 \pm 9.3 \mathrm{vs}$. $2.9 \pm 0.5 \mathrm{ng} / \mathrm{ml} \mathrm{respectively}$, p<0.01, with an optimal cut point of $\geq 5.5 \mathrm{ng} / \mathrm{ml}$ to predict RPL (Ozkan et al 2014). This disagreement with our findings could be caused by the RPL cases were included in both studies (Saito et al, 2010).

In the current study IL17 was seen to be correlated directly with CMV IgM level in both healthy control and RPL groups at a similar degree. Furthermore, IL17 was correlated directly with CMV IgG avidity in the RPL group only $(\mathrm{p}<0.05)$, but no correlation with CMV IgG. TGF $\beta$ was noted to be inversely connected with IgM in the control group $(\mathrm{p}<0.05)$, and no correlation was recorded in the RPL group. In addition, TGF $\beta$ was not corresponded with CMV IgG or CMV IgG avidity in all studied groups. In conclusion, we found that CMV infection was directly correlated with high levels of IL17 in serum, but no correlation was seen between CMV infection and levels of TGF $\beta$.

\section{References:-}

1. Ahmed Z.K., Salman, Z.Q. (2014).Quantitative Detection of Human Cytomegalovirus (HCMV) Gene in Iraqi Women with Pregnancy Associated Problems. Iraqi Journal of Biotechnology, vol.13, No.1, 30-38.

2. Aljumaili, Z.K., Alsamarai, A.M., Najem, W.S.:(2014).Cytomegalovirus seroprevalence in women with bad obstetric history in Kirkuk, Iraq. J Infect Public Health;7(4):277-88.

3. Al-Jiffri, O., Al-Sharif, F. M. and El-Sayed, Z. M.:(2013). Seroprevalence of Cytomegalovirus among Donors and Other Investigated Groups . Intl. J. Microbial. Res. 4(1) :1-8.

4. Cannon, M.J., Schmid, D.S., Hyde, T.B. (2010).Review of cytomegalovirus seroprevalence and demographic characteristics associated with infection. Rev Med Virol. 20(4):202-13.

5. Darmochwal-Kolarz, D., Michalak, M., Kolarz, B., Monika Przegalinska-Kalamucka.(2017). The Role of Interleukin-17, Interleukin-23, and Transforming Growth Factor- $\beta$ in Pregnancy Complicated by Placental Insufficiency. BioMed Research International.vol.2017, Article ID 6904325, 5 pages.

6. Darmochwal-Kolarz, D., Kludka-Sternik ,M., Tabarkiewicz , J. (2012).“The predominance of Th17 lymphocytes and decreased number and function of Treg cells in preeclampsia," Journal of Reproductive Immunology, vol. 93, no. 2, pp. 75-81,

7. Duff,P. A (2007).thoughtful algorithm for the accurate diagnosis of primary CMV infection in pregnancy. Am $\mathbf{J}$ Obstet Gynecol March, pp. 196-197.

8. Fischer, A.:( 2008).Human immunodeficiency: connecting STAT3, Th17 and human mucosal immunity. Immunol Cell Biol;86:549-51.

9. Ford, H. B; Schust D. J.(2009). Recurrent Pregnancy Loss: Etiology, Diagnosis, and Therapy. Rev Obstet Gynecol. 2(2): 76-83.

10. Fowler, K.B.; Stagno, S.; Pass, R.F.; Britt, W.J.; Boll, T.J.; Alford, C.A. (1992).The outcome of congenital cytomegalovirus infection in relation to maternal antibody status. N Engl J Med;326:663-667.

11. Gaffen, S. L. (2009). "Structure and signalling in the IL-17 receptor family," Nature Reviews Immunology, vol. 9, no. 8, pp. 556-567.

12. Gaytant, M.A., Rours, G.I., Steegers, E.A., Galama, J.M., Semmekrot, B.A.(2003).Congenital cytomegalovirus infection after recurrent infection: case reports and review of the literature. Eur J Pediatr. 162(4):248-53.

13. Giannubilo, S.R., Landi, B., Pozzi, V. (2012).The involvement of inflammatory cytokines in the pathogenesis of recurrent miscarriage. Cytokine 2012;58:50-6.

14. Happel, K. I., Dubin, P. J., Zheng, M. (2005). Divergent roles of IL-23 and IL-12 in host defense against Klebsiella pneumoniae, The Journal of Experimental Medicine. 202, no. 6, pp. 761-769.

15. Hananchi, N. ,Marzouk, M. , Harrabi, I. , Ferjani, A. and Ksouri, Z.:(2011). Seroprevalence of rubella virus, varicella zoster virus, cytomegalovirus and parvovirus B19 among pregnant women in the Sousse region, Tunisia. Bull. Soc. Pathol. Exot. 104 :62 - 67.

16. Harrington, L.E., Hatton, R.D., Mangan, P.R,:(2005). Interleukin 17-producing CD4+ effector T cells develop via a lineage distinct from the T helper type 1 and 2 lineages. Nat Immunol;6:1123-32.

17. Hazell, S.L. (2007). Clinical utility of avidity assays. Expert Opin. Med. Diagn. 1:511-519. 10.1517/17530059.1.4.511.

18. Hussan,B.M.(2013).Study the prevalence of ACL,APL,CMV,HSV, Rubella and Toxoplasma gondii in aborted women in Baghdad. Medical Journal of Babylon.10 (2) :455-464.

19. Huang, W. L. N, Fidel P. L, Schwarzenberger, P.(2004). "Requirement of interleukin-17A for systemic antiCandida albicans host defines in mice," Journal of Infectious Diseases, vol. 190, no. 3, pp. 624-631. 
20. Ito, M., Nakashima, A., Hidaka, T.(2010). "A role for IL-17 in induction of an inflammation at the fetomaternal interface in preterm labour," Journal of Reproductive Immunology, vol. 84, no. 1, pp. 75-85.

21. Kriel, R.L., Gates, G.A., Wulff, H., Powell, N., Poland, J.D., Chin, T.D. (1970). Cytomegalovirus isolations associated with pregnancy wastage. Am J Obstet Gynecol.15; 106(6):885-92.

22. Kuwabara, T., Ishikawa, F., Kondo, M., and Kakiuchi, T.(2017). The Role of IL-17 and Related Cytokines in Inflammatory Autoimmune Diseases. Mediators of Inflammation. Article ID 3908061, 11 pages.

23. Letterio, J. J. and Roberts. A. B. (1998). "Regulation of immune responses by TGF- $\beta$," Annual Review of Immunology, vol. 16, pp. 137-161.

24. Li, M.O., Wan, Y.Y., Sanjabi, S., Robertson, A.K., Flavell, R.A. (2006).Transforming growth factor-beta regulation of immune responses. Annu Rev Immunol. 24:99-146.

25. Liu, Y.S., Wu, L., Tong, X.H.:(2011). Study on the relationship between Th17 cells and unexplained recurrent spontaneous abortion. Am J Reprod Immunol;65:503-11.

26. Macklon, N.S., Geraedts, J.P.M., Fauser, B.C.J.M. (2002).Conception to ongoing pregnancy: the "black box" of early pregnancy loss. Hum Reprod Update.8:333-343.

27. Nakashima, A., Ito, M., Shima, T. Bac, N. D., Hidaka, T. and Saito, S. (2010). "Accumulation of IL-17positive cells in decidua of inevitable abortion cases," American Journal of Reproductive Immunology, vol. 64, no. 1, pp. $4-11$.

28. Najafi, S, Hadinedoushan, H., Eslami, G. (2014). Association of IL-17A and IL-17 F gene polymorphisms with recurrent pregnancy loss in Iranian women. J Assist Reprod Genet .31:1491-1496. DOI 10.1007/s10815-0140294-0.

29. Naundorf, S., Schro"der, M., Ho“ flich, C.:(2009). IL-10 interferes directly with TCR-induced IFN-gamma but not IL-17 production in memory T cells. Eur J Immunol;39:1066-77

30. Nigro, G., Adler,S.P.(2011).Cytomegalovirus infections during pregnancy. Curr Opin Obstet Gynecol. 23(2):123-8.

31. Nigro, G.(2009). Maternal-fetal cytomegalovirus infection: from diagnosis to therapy. J Matern Fetal Neonatal Med;22:169-174.

32. Odland, J., Irina, I.V., Ivaneev, M.D.:(2001). Seropositivity of cytomegalovirus, parvovirus and rubella in pregnant women and recurrent aborters in Leningrad County, Russia. Acta Obstet Gynecol Scand; 80: 10251029.

33. Ozkan, Z.S., Devec1, D., Simsek, M., :(2014).What is the impact of SOCS3, IL-35 and IL17 in immune pathogenesis of recurrent pregnancy loss?, The Journal of Maternal-Fetal \& Neonatal Medicine. 28:3, 324-328, DOI: $10.3109 / 14767058.2014 .916676$.

34. Pass, R.F., Anderson, B.:(2014). Mother-to-Child Transmission of Cytomegalovirus and Prevention of Congenital Infection. J Pediatric Infect Dis Soc; 3(Suppl 1): S2-S6.

35. Raghupathy, R., Makhseed, M., Azizieh, F, :(2000).Cytokine production by maternal lymphocytes during normal human pregnancy and in unexplained recurrent spontaneous abortion. Hum Reprod;15: 713-18.

36. Sadik, M.S., Fatima, H., Jamil, K., Patil, C.:(2012). Study of TORCH profile in patients with bad obstetric history. Biology and Medicine, 4 (2): 95-101.

37. Saito, S., Nakashima A, Shima T, Ito M.:( 2010). Th1 / Th2 / Th17 and regulatory T-cell paradigm in pregnancy. Am J Reprod Immunol; 63: 601-610. doi:10.1111/j.1600-0897.2010.00852.x

38. Sherkat, R. , Meidani, M., Zarabian, H., Rezaei, A., and Gholamrezaei, A. (2014). Seropositivity of cytomegalovirus in patients with recurrent pregnancy loss. J Res Med Sci. 19(Suppl 1): S22-S25.

39. Stein, O., Sheinberg, B., Schiff, E., :(1997).Prevalence of antibodies to cytomegalovirus in a parturient population in Israel. Isr J Med Sci; 33: 53-8.

40. Stephenson, M.D.(1996). Frequency of factors associated with habitual abortion in 197 couples. Fertil Steril.66:24-29.

41. Walshe, T. E., Saint-Geniez. M., Maharaj, A. S. R., Sekiyama, E., Maldonado, A. E., and D'Amore, P. A.(2009)."TGF- $\beta$ is required for vascular barrier function, endothelial survival and homeostasis of the adult microvasculature," PLoS ONE, vol. 4, no. 4, Article ID e5149.

42. Zaki, M.E., Goda, H. (2007). Relevance of Parvovirus B19, Herpes Simplex Virus 2, and Cytomegalovirus Virologic Markers in Maternal Serum for Diagnosis of Unexplained Recurrent Abortions. Arch Pathol Lab Med.131:956-960. 